\title{
Relationship between a network's indicators and basic factors with high-risk behavior of injection among injecting drug users (IDU) via the multiple membership multilevel model
}

\author{
Ali Karamoozian ${ }^{1}$, Yunes Jahani ${ }^{2,3}$, Armita Shahesmaeili ${ }^{4}$, Moghaddameh Mirzaee ${ }^{2,3}$
}

${ }^{1}$ M.Sc. of Biostatistics, Modeling in Health Research Center, Institute for Futures Studies in Health, Kerman University of Medical Sciences, Kerman, Iran

${ }^{2}$ Ph.D. of Biostatistics, Assistant Professor, Modeling in Health Research Center, Institute for Futures Studies in Health, Kerman University of Medical Sciences, Kerman, Iran

${ }^{3} \mathrm{Ph} . \mathrm{D}$. of Biostatistics, Assistant Professor, Department of Biostatistics and Epidemiology, School of Public Health, Kerman University of Medical Sciences, Kerman, Iran

${ }^{4}$ Ph.D. of Epidemiology, Assistant Professor, HIV/STI Surveillance Research Center, and WHO Collaborating Center for HIV Surveillance, Institute for Futures Studies in Health, Kerman University of Medical Sciences, Kerman, Iran

\section{Type of article: Original}

\begin{abstract}
Background: Among various methods and types of drug abuse, injection receives a great deal of importance because of its related dangerous behavior and health consequences. It seemed that some of the network's indicators affect dangerous behavior of injection.

Objective: To determine the relationship between a network's indicators and basic factors with high-risk behavior of injection among injecting drug users (IDU) via the multiple memberships multilevel model.

Methods: In this cross-sectional study, the data related to 147 IDUs in Kerman province, who were interviewed from October 2013 through March 2014, were used, and these addicts were chosen for interview from specific resorts used for common injection. In this study, for analyzing data, multiple membership multilevel model and MLwiN 2.02 software were used.

Results: In this study, the mean age of people, who were mostly men, was $37.2 \pm 9.02$. Based on the result, it becomes obvious that variables of in-degree with $\mathrm{OR}=1.49(\mathrm{p}=0.006)$ and the whole number of people related to the person with $\mathrm{OR}=1.18(\mathrm{p}=0.003)$ influences the high-risk behavior of injection. Also, none of the demographic variables influenced the high-risk behavior of injection.

Conclusion: Totally based on the results of this study, one can find a suitable method in the social network of IDUs in order to create essential strategies, reducing the risk throughout the country. In addition, in minimum time with fewer expenses, aggravation of dangerous behavior especially high-risk behavior of injection can be prevented.
\end{abstract}

Keywords: Multilevel analyses; Social network; Dangerous behaviors; Drug user; Injection

\section{Introduction}

One of the most important health difficulties worldwide and especially in Iran is drug abuse. Among the various methods of drug abuse, injection receives a higher importance because of its health consequences. There is estimated to be 13.2 million injecting drug users (IDU) worldwide. In Iran, there are a minimum of two hundred thousand IDUs who are mostly men (1). Addiction to injection causes infectious viruses like hepatitis B and C, and HIV. IDUs have an important role in transmitting these viruses to those who are not drug injectors, and this issue leads to the spread and outbreak of these infections in society. In addition, this is the social network where IDUs are

\section{Corresponding author:}

Yunes Jahani, Kerman University of Medical Sciences, Kerman.

Tel: +98.3431325421, Email: Yunesjahani@Yahoo.Com

Received: January 22, 2017, Accepted: June 03, 2017, Published: September 2017

iThenticate screening: May 31, 3017, English editing: September 01, 2017, Quality control: September 10, 2017

This article has been reviewed / commented by three experts

(C) 2017 The Authors. This is an open access article under the terms of the Creative Commons Attribution-NonCommercialNoDerivs License, which permits use and distribution in any medium, provided the original work is properly cited, the use is non-commercial and no modifications or adaptations are made. 
in relation with many non-addicted people $(2,3)$. The social network consists of unit collections named nodes or actors, and the relationship between them is tie or link. Nodes are the actual people $(4,5)$. When all nodes and ties are clear and obvious, it is possible to draw a portrait of a network and the people's location there. Also we can talk about the distance between people (6). In the social network, tie is not limited only to friends but to many people who may be in touch with him/her without any kinship or rapport. In fact, the social network of a person is made up of all people who are in touch with that particular person in question directly or indirectly, like networks of friends, family, coworkers or even drug abusers, and actually it is concluded of all people who influence each other's behavior based on social reactions between each other (4-6). The first analysis of a social network was done in 1934 by Joseph Moreno (4). The analysis of a social network helps us to understand how a social phenomenon spreads along the network, and affects people's health. Also, in this method we can study the structure of relationship between people and their internal relevance manner. In other words, the analysis of the social network shows the social structure in a group in order to clarify the unsystematic relationships among people. And these relationships are mostly in the form of correspondence, signal, belief and intimacy (7-9). Risk network is a group of people who experience high-risk, and mostly, risk network and social network are overlapped. In a study done in New York, $70 \%$ of IDUs used the same injection tools with family members, sex partners, friends and relatives $(10,11)$. Highrisk behaviors are conscious or unconscious behaviors that increase the chance of getting diseases. High-risk behaviors also have different types and kinds, that in this study, is acknowledged by dangerous behavior of injection. The usual method of epidemiological study analysis is not fruitful in this study of people's social network because of different reasons. For example, the use of a regression model is reliable only when the observations are independent from each other, though the health status of a population comes from behavior, interaction, and communication among people that have formed it. Furthermore, these social relationships between people violate the main assumption of independency of observations (7). Since people within the same group have almost the same and incidental behavior, using the multilevel analysis method is essential and fruitful. Because in a social network each individual may be associated with more than one group, it violates the multilevel hierarchical model. Therefore, for analyzing the network's input and solving this problem, we use the multiple membership multilevel model (12-14). This method was first used in 1998 by Hill and Goldstein (15-17). Also, studies about high-risk behavior of injection and its related factors in a social network via multiple membership of multilevel model and other possible models have been done in America, France, Canada, and Iran between 2000 and 2015 (2, 5, 18-25). The result of this study will be compared with those results. The mentioned method is used when each lower level unit synchronously is a member of more than one higher level unit, thus in the multiple membership model based on the amount of possessions, weight is attributed, and its effects on the exact consequence become the model $(15,16)$. As using a drug, especially an injection drug, has caused a lot of problems like illnesses such as HIV and hepatitis and also the amount of this kind of drug use has been increasing daily in most societies, especially Iran, we preferred to conduct a research on the role of decreasing this amount. On the other hand, considering that injection addicts may present in several resorts for common injection during a period, we chose a model which could consider this and in which presence of addicts in several resorts did not elicit a problem. So, the model which could fit these data was a multiple membership multilevel model. The objective of this study is to determine the relationship between the network's indicators and basic factors with high-risk behavior of injection among IDUs via the multiple membership multilevel model.

\section{Material and Methods}

\subsection{Study population and sampling}

All the data were collected in Kerman province from October 2013 through March 2014 via standardized questionnaires administered by skillful interviewers to people under study, who were above 18 years old. The people under study were those who had experienced injection at least once during the previous year and had not participated in a study during the previous two months. The method of sampling used here is a network sampling, which is similar to respondent driven sampling (RDS), with the difference being that in this sampling, unlike the RDS method that every person nominates a certain number of people having inclusion criteria in this study, the person should nominate all people, having inclusion criteria, associated with them. On the interview day, it should be clear who these people are in order to distinguish their relationship and ask them about their features. Based on this, first, 15 active leaders with high public relation ability were chosen and were asked to nominate up to 20 people who were in touch with them during last month. Then, they were asked whether each nominee is a drug injector or not. If not, they were asked to nominate all people who had injected with them. The task continued until no more extra information was added to inputs. Eventually, via this method, 147 IDUs were studied and according to people's introduction, the whole network included 433 IDUs. 


\subsection{Variables}

For fitting the multiple membership multilevel model in this study, response variable is named high-risk behavior of injection and this variable is a binary variable. In fact, it is the response to the question of whether they had common injection or not. Basic independent variables are inclusive of age, education, gender and marital status. The rest of the variables, which are all network indicators, are the situation (location) of people in risk network, in-degree, outdegree, the whole number of IDUs that were associated with him/her during the previous month, the whole number of people introduced by him/her, reciprocity and component. Since the population of IDUs is an open population, calculating all the indicators related to network is impossible. Below we define the indicators of which calculating them was made possible in this study and we can use them in a model:

1) Network location: each person's location is compared to others' location in a network that is made up of four levels: The core of the main component, members of the main component, members of the small component and isolated/unlinked people.

2) Component: It is made up of all people who are directly or indirectly associated with each other. In this study, the component is the number of people that the person is associated with, either directly or indirectly.

3) Reciprocity: It shows the relation of mutual relationship to the whole relationships.

4) In-degree: It is the number of times that a person is nominated by others. The more the in-degree of a person, the more well-known he/she would be.

5) Out-degree: The number of people nominated by a person. The more the out-degree of a person, the more sociable he/she would be.

\subsection{Method of modeling}

In this section, we fitted multiple membership multilevel model (26). First, we added all the basic independent variables and variables of network indicators as a single variable to the model. Then in a multivariable case, based on the role of component variable and reciprocity variable in formation of location variable and strong correlation of these two variables to location variable of people in risk network, we declined to add them in model and we just added location variable to the model. Next, we added all the variables having the p-value of less than 0.2 with location variable to the model. And, via the use of backward method, we reached the ideal model. For all the model's variables, odds ratio, confidence interval for odds ratio and $p$-value were reported. Also in this study, the analyses were evaluated by MLwiN 2.02 software (16). Since some of the lower level units were members of more than one higher level unit, we attributed belonging weight to this amount. There are two methods of determining the amount of belonging weight of each person to different personal networks: The first method is the suggesting weighting schema of Tranmer and colleagues that if a person nominates " $n$ " people in his/her personal network, each nominee is given a weight of " $1 / \mathrm{n}$ " in weight matrix (27). The second method is based on the amount of time that each unit of lower level in personal network (upper level unit) uses and based on that time, each unit is given weight (16). It should be noted that both methods are based on the fact that the total weight in each unit of the first level is one. In this study, for more accurate results and better understanding of relationship's intensity, we used the method of weighting schema based on the used time in the network for each unit of weight.

\subsection{Ethical consideration}

The study protocol was approved by the ethics committee of the Kerman University of Medical Sciences (Ethics code No: K/94/382). Before interviewing, some explanations of this research's goals were given to addicts, and only those who accepted it, cooperated. Considering that most of the questions were related to personal and private relations, they were assured that their whole data would remain confidential.

\section{Results}

You can see the described results of study's variables in Tables 1 and 2 that for quantitative variables the average and standard deviation, and for qualitative variables frequency and percentage were calculated. As you can notice in this study, the mean age of people, who are mostly men, is $37.2 \pm 9.02$. More than half of these people are single, and have less than high school education. As we fitted the multiple membership multilevel model, the results are noticeable in Tables 3 and 4. In Table 3, the multiple membership multilevel logistic regression model of single variable and in Table 4 the multiple membership multilevel logistic regression model of multivariable have been fitted. Based on the results of multiple membership multilevel of single variable, none of the demographic variables made, were significant in this study. We could observe meaning in most of the network indicators in this study. In the final version of the model in the multivariable case, it was observed that just in-degree and the whole number of people related to person variable were statistically significant. While location variable, out-degree and the number of 
IDUs related to the person were not statistically significant. If the in-degree variable, which is the number of times that a person is nominated by others, increased for a unit, the person would be under influence of the high-risk behavior of injection by $49 \%$ more than usual. Also, by adding one person to the whole number of people related to the person, the odds of being influenced by high-risk behavior of injection increased by $18 \%$.

Table 1. Frequency distribution of demographic variables and network indicators of 147 IDUs

\begin{tabular}{|l|l|l|}
\hline Characteristic & \multicolumn{1}{|l|}{ Value [n (\%)] } \\
\hline Gender & Female & $13(8.8)$ \\
\cline { 2 - 3 } & Male & $134(91.2)$ \\
\hline \multirow{4}{*}{ Education } & Primary school & $52(35.4)$ \\
\cline { 2 - 3 } & Guidance school & $56(38.1)$ \\
\cline { 2 - 3 } & High school & $39(26.5)$ \\
\hline \multirow{4}{*}{ Marital status } & Single & $76(51.7)$ \\
\cline { 2 - 3 } & Married & $41(27.9)$ \\
\cline { 2 - 3 } & Divorced & $30(20.4)$ \\
\hline & Individual & $44(29.9)$ \\
\cline { 2 - 3 } & Members of small component & $33(22.4)$ \\
\cline { 2 - 3 } & Members of main component & $23(15.6)$ \\
\cline { 2 - 3 } & Central component & $47(32.1)$ \\
\hline
\end{tabular}

Table 2. Central and dispersed indicators of demographic variables and network indicators of 147 IDUs

\begin{tabular}{|l|l|l|l|}
\hline Characteristic & Minimum & Maximum & Mean \pm SD \\
\hline Age (year) & 20 & 63 & $37.2 \pm 9.02$ \\
\hline Component & 1 & 14 & $3.29 \pm 3.61$ \\
\hline Out-Degree & 0 & 7 & $1.45 \pm 1.53$ \\
\hline In-Degree & 0 & 12 & $1.45 \pm 1.75$ \\
\hline Number of injected people related to the person & 0 & 13 & $2.91 \pm 2.67$ \\
\hline Number of all people related to the person & 0 & 18 & $7.24 \pm 4.01$ \\
\hline Reciprocity & 0 & 1 & $0.49 \pm 0.41$ \\
\hline
\end{tabular}

SD: Standard deviation

Table 3. The multiple membership multilevel logistic regression analysis of single variable in determining the relation between network indicators and basic factors with high-risk behavior of injection among IDUs

\begin{tabular}{|l|l|l|l|l|}
\hline Characteristic & OR & $95 \%$ CI for OR & p-value \\
\hline Age (year) & Female & 1.02 & $(0.98-1.05)$ & 0.34 \\
\hline \multirow{2}{*}{ Gender } & Male & 1 & - & - \\
\hline \multirow{3}{*}{ Education } & Primary school & 0.57 & $(0.14-2.27)$ & 0.43 \\
\cline { 2 - 5 } & Guidance school & 1 & - & - \\
\cline { 2 - 5 } & High school & 1.43 & $(0.55-3.66)$ & 0.45 \\
\hline \multirow{3}{*}{ Marital status } & Single & 1.13 & $(0.39-3.25)$ & 0.81 \\
\cline { 2 - 5 } & Married & 1 & - & - \\
\cline { 2 - 5 } & Divorced & 1.34 & $(0.6-3)$ & 0.46 \\
\hline \multirow{3}{*}{ Location } & Individual & 1.05 & $(0.44-2.45)$ & 0.91 \\
\cline { 2 - 5 } & Members of small component & 1 & - & - \\
\cline { 2 - 5 } & Members of main component & 1.82 & $(0.74-4.48)$ & 0.19 \\
\cline { 2 - 5 } & Central component & 4.66 & $(1.57-4.3)$ & 0.38 \\
\hline Out-Degree & 1.68 & $(1.25-2.24)$ & $<0.001$ \\
\hline In-Degree & 1.55 & $(1.18-2.03)$ & 0.0016 \\
\hline The number of injected people related to the person & 1.43 & $(1.16-1.76)$ & 0.001 \\
\hline The whole people related to the person & 1.19 & $(1.08-1.32)$ & $<0.001$ \\
\hline Reciprocity & 1.05 & $(0.41-2.69)$ & 0.9 \\
\hline Component & 1.03 & $(0.93-1.13)$ & 0.56 \\
\hline
\end{tabular}

OR: Odds ratio; CI: Confidence interval 
Table 4. The multiple membership multilevel logistic regression analysis of multivariable in determining the relation between network indicators and basic factors with high-risk behavior of injection among IDUs

\begin{tabular}{|l|l|l|l|}
\hline Characteristic & Adjusted OR & 95\% CI for OR & p-value \\
\hline Intercept & 0.3 & $(0.12-0.75)$ & 0.01 \\
\hline In-Degree & 1.49 & $(1.13-1.95)$ & 0.006 \\
\hline Whole number of people related to the person & 1.18 & $(1.06-1.32)$ & 0.003 \\
\hline
\end{tabular}

OR: Odds ratio; CI: Confidence interval

\section{Discussion}

In this study, the effect of demographic variables and network indicators on high-risk behavior of injection were analyzed via the use of a multiple membership multilevel model in two methods of single variable and multivariable. The effect was that none of the demographic variables were statistically significant and in the multivariable case only the in-degree variable and the whole number of people related to the person were statistically significant. Since the in-degree variable is the number of times that a person is nominated and in other words is indicating variable of fame for the person in risk network, we can conclude that when a person is nominated many times, the person must have been associated with many IDUs and must have belonged to more injection shelters than others. Thus because of that which was stated before, the person can influence starters better than others especially when this person, because of his/her fame among drug injectors acts firmly enough that others follow his beliefs and thoughts better than other drug injectors, hence they inject more and more and this causes their high-risk behavior of injection to be influenced. Now from another perspective, we can lead the discussion this way: Since the famous people of a network are those who are nominated many times by other members of the network, we expect these people to be associated with many other IDUs and to be present in many injection locations for injection. This shows that these people inject more frequently than others. Based on the results of this study as meaningful census, we believe that the more famous the person, the more frequently the person had injected. In other words, high-risk behavior of injection influences the person in question better than others. In the study done by Costenbader and colleagues in some parts of Baltimore, America, 2006 in order to analyze the relationship of demographic variables and some network's indicators with high-risk behavior of injection for having the risk of transmitting HIV, it was shown to be similar to our study that in-degree variable had the greatest influence on high-risk behavior of injection (21). Another variable, which was statistically significant in this study, was the variable of all people associated with the person in question. As the person is in connection with more people, he is more influenced by the beliefs and different attitudes. This causes him to be more influenced by others' behavior. And now, as the person is injected and most of the people in connection with him are addicts or drug injectors, the person craves for injection and especially frequent injection more than before. It means the person is much more influenced by high-risk behavior of injection. This study's results are proof to the claim that this study is clear and obvious and to the claim of being a meaningful study, we can mention Week's and colleagues' study in Hartford, America, 2001 that was in conformity with our study (19). As none of the demographic variables of this study were statistically significant, and based on the agreement of our study with other studies done in a network level like Valente and colleagues in America, 2000 (18), Lovell in France, 2002 (2), Shaw and colleagues in Canada, 2004 (20), Wylie and colleagues in Canada, 2006 (22), Unger and colleagues in America, 2006 (23), Havens and colleagues in America, 2011 (24), Tracy and colleagues in America, 2012 (25), and Shahesmaeili in Iran, 2014 (5), we can get that maybe because of data structure in the level of network, demographic variables like age and gender, have a slight influence on high-risk behavior of injection. On the other hand, based on the definition of high-risk behavior of injection, which considers both conscious and unconscious behaviors, we could get that marital status, education, age and gender cannot influence high-risk behavior of injection. Maybe the other reason of not making sense is that in this study, only high-risk behavior of injection is considered and IDUs, after a while, face physical and emotional problems of injection, these variables cannot influence high-risk behaviors. Nonetheless, we observed in this study that demographic variables do not influence high-risk behavior of injection and we need to think of essential strategies for just some of the networks indicators. Here, the in-degree variable and the whole number of people related to the person variable were statistically significant; thus, we conclude that these two variables increase the likelihood of contracting diseases related to injection. Therefore, it is better to decrease high-risk behavior of injection, which leads to an increase in the likelihood of contracting diseases like HIV, Hepatitis B and $\mathrm{C}$ in future, the essential decides about in-degree and the whole number of people related to him should be made. Since IDUs play an important role in transmitting viruses to non-addicted people, via conscious strategies and decisions, we can prevent the spread of these infections in society. As a suggestion via the use of in-degree people, we can detect famous people of the network and instead of spending great deals of time and money for taking care of all the people in the network, via some efficient plan; we can take care of famous people. Essential arrangements 
should be done to decrease the chance of getting diseases and high-risk behavior of injection in minimum time with fewer expenses. Also, we can control the person or do something in order to lessen the person's relation with those IDUs to cause the decrease of high-risk behavior of injection.

\section{Limitations}

Our study had a problem that was the disability of analyzing all network indicators because under study society was open. Although this problem limits us in showing the complete structure of drug injectors, it causes no problem in our process of modeling.

\section{Conclusions}

Based on this study, we can conclude that in this study with network structure which we analyzed, the relationship between indicators of individual levels like age and gender, influences high-risk behavior of injection slightly. But some of the network level indicators like in-degree and whole number of people related to person can influence dangerous behavior of injection greatly. Totally based on the results of this study, we can find a suitable method in social network of IDUs in order to create essential strategies for reducing the risk nationwide. In addition, in minimum time with fewer expenses, aggravation of high-risk behaviors especially high-risk behavior of injection, can be prevented. Also, via essential strategies, something should be done in order to reduce the daily outbreak of related diseases to common injection, especially Aids and hepatitis B.

\section{Acknowledgments:}

Finally, we are so grateful to Professor William J. Browne (University of Bristol, Bristol, England) and Professor Mark Tranmer (University of Manchester, Manchester, England) for their guidance regarding the method of using the multiple membership multilevel model with the binary response variable in MLwiN software. Furthermore, we are so thankful to the great professors who helped us patiently from the beginning up to the end of this study. This project was the result of a M.Sc. thesis in Kerman University of Medical Sciences.

\section{Conflict of Interest:}

There is no conflict of interest to be declared.

\section{Authors' contributions:}

All authors contributed to this project and article equally. All authors read and approved the final manuscript.

\section{References:}

1) Aceijas $C$, Stimson GV, Hickman M, Rhodes T. Global overview of injecting drug use and HIV infection among injecting drug users. Aids. 2004; 18(17): 2295-303. doi: 10.1097/00002030-200411190-00010. PMID: 15577542.

2) Lovell AM. Risking risk: the influence of types of capital and social networks on the injection practices of drug users. Soc Sci Med. 2002; 55(5): 803-21. doi: 10.1016/S0277-9536(01)00204-0. PMID: 12190272.

3) Booth RE, Kwiatkowski CF, Chitwood DD. Sex related HIV risk behaviors: differential risks among injection drug users, crack smokers, and injection drug users who smoke crack. Drug alcohol depend. 2000; 58(3): 219-26. doi: 10.1016/S0376-8716(99)00094-0. PMID: 10759032.

4) Ehrlich K, Carboni I. Inside social network analysis. Boston College. 2005.

5) Shahesmaeili A, Haghdoost AA, Soori H. Network Location and Risk of Human Immunodeficiency Virus Transmission among Injecting Drug Users: Results of Multiple Membership Multilevel Modeling of Social Networks. Addict health. 2015; 7(1-2): 1-13. PMID: 26322205, PMCID: PMC4530188.

6) Christakis NA, Fowler JH. Social network visualization in epidemiology. Nor epidemiol. 2009; 19(1): 5. PMID: 22544996, PMCID: PMC3337680.

7) El-Sayed AM, Scarborough P, Seemann L, Galea S. Social network analysis and agent-based modeling in social epidemiology. Epidemiol Perspectiv Innov. 2012; 9(1): 1. doi: 10.1186/1742-5573-9-1. PMID: 22296660, PMCID: PMC3395878.

8) Luke DA, Harris JK. Network analysis in public health: history, methods, and applications. Annu Rev Public Health. 2007; 28: 69-93. doi: 10.1146/annurev.publhealth.28.021406.144132. PMID: 17222078.

9) Marshall BD, Wood E, Shoveller JA, Buxton JA, Montaner JS, Kerr T. Individual, social, and environmental factors associated with initiating methamphetamine injection: implications for drug use and HIV prevention strategies. Prevention Science. 2011; 12(2): 173-80. doi: 10.1007/s11121-010-0197-y. PMID: 21274628, PMCID: PMC3107866. 
10) Dunn J, Ferri CP. Epidemiological methods for research with drug misusers: review of methods for studying prevalence and morbidity. Revista de Saúde Pública. 1999; 33(2): 206-15. PMID: 10413939.

11) Friedman SR, Neaigus A, Jose B, Curtis R, Des Jarlais D. Networks and HIV risk: an introduction to social network analysis for harm reductionists. International Journal of Drug Policy. 1998; 9(6): 461-9.

12) Chung H, Beretvas SN. The impact of ignoring multiple membership data structures in multilevel models. British Journal of Mathematical and Statistical Psychology. 2012; 65(2): 185-200. doi: 10.1111/j.20448317.2011.02023.x. PMID: 21732931.

13) Fielding A, Goldstein H. Cross-classified and multiple membership structures in multilevel models: an introduction and review. 2006.

14) Chandola T, Clarke P, Wiggins R, Bartley M, editors. Households: the missing level of analysis in multilevel epidemiological studies: the case for multiple membership models. British Household Panel Survey Research Conference, Colchester, UK; 2003.

15) Beretvas SN. Cross-classified and multiple membership models. Handbook of advanced multilevel analysis. 2011: 313-34.

16) Leckie G, Owen D. Module 13: Multiple Membership Multilevel Models MLwiN Practical. Centre for Multilevel Modelling. 2013.

17) Hill PW, Goldstein H. Multilevel modeling of educational data with cross-classification and missing identification for units. Journal of Educational and Behavioral statistics. 1998; 23(2): 117-28. doi: 10.3102/10769986023002117.

18) Valente TW. Social networks and health: Models, methods, and applications. New York: Oxford. 2010.

19) Weeks MR, Clair S, Borgatti SP, Radda K, Schensul JJ. Social networks of drug users in high-risk sites: Finding the connections. AIDS and Behavior. 2002; 6(2): 193-206. doi: 10.1023/A:1015457400897.

20) Shaw SY, Shah L, Jolly AM, Wylie JL. Determinants of injection drug user (IDU) syringe sharing: the relationship between availability of syringes and risk network member characteristics in Winnipeg, Canada. Addiction. 2007; 102(10): 1626-35. doi: 10.1111/j.1360-0443.2007.01940.x. PMID: 17854339.

21) Costenbader EC, Astone NM, Latkin CA. The dynamics of injection drug users' personal networks and HIV risk behaviors. Addiction. 2006; 101(7): 1003-13. doi: 10.1111/j.1360-0443.2006.01431.x. PMID: 16771892 .

22) Wylie JL, Shah L, Jolly A. Incorporating geographic settings into a social network analysis of injection drug use and bloodborne pathogen prevalence. Health place. 2007; 13(3): 617-28. doi: 10.1016/j.healthplace.2006.09.002. PMID: 17074527.

23) Unger JB, Kipke MD, De Rosa CJ, Hyde J, Ritt-Olson A, Montgomery S. Needle-sharing among young IV drug users and their social network members: The influence of the injection partner's characteristics on HIV risk behavior. Addictive behaviors. 2006; 31(9): 1607-18. doi: 10.1016/j.addbeh.2005.12.007. PMID: 16459023.

24) Havens JR, Oser CB, Knudsen HK, Lofwall M, Stoops WW, Walsh SL, et al. Individual and network factors associated with non-fatal overdose among rural Appalachian drug users. Drug and alcohol dependence. 2011; 115(1): 107-12. doi: 10.1016/j.drugalcdep.2010.11.003. PMID: 21126831, PMCID: PMC3056907.

25) Tracy EM, Kim H, Brown S, Min MO, Jun MK, McCarty C. Substance abuse treatment stage and personal networks of women in substance abuse treatment. J Soc Social Work Res. 2012; 3(2): 65. doi: 10.5243/jsswr.2012.5. PMID: 22639705, PMCID: PMC3358724.

26) Rasbash J, Browne WJ. Modelling non-hierarchical structures. Multilevel modelling of health statistics. 2001: 93-105.

27) Tranmer M, Steel D, Browne WJ. Multiple membership models for social network and group dependencies. 2012. doi: 10.1111/rssa.1202. PMID: 25598585, PMCID: PMC4282334. 